\title{
A epidemiologia do teletrabalhador: impactos do teletrabalho na saúde mental ${ }^{1}$
}

\author{
Regina Lúcia de Almeida Fonseca e Amalia Raquel Pérez-Nebra \\ Faculdade de Ciências da Saúde e Educação, \\ Centro Universitário de Brasília (Brasília, DF)
}

\begin{abstract}
O presente estudo encontrou embasamento na visão da epidemiologia do trabalho, de Codo, Soratto e VasquesMenezes (2004), com o objetivo de identificar os impactos psicológicos do teletrabalho na saúde mental dos teletrabalhadores. Vale ressaltar que a saúde mental foi tomada como variável de interesse e associada às três dimensões que abordam o campo da saúde mental no trabalho: a relação homem-natureza, a relação homemsociedade e a relação do homem consigo mesmo. Responderam à pesquisa 90 teletrabalhadores. Dentre os resultados, verificou-se que os teletrabalhadores atuam, principalmente, nas áreas de comunicação e tecnologia da informação. A pesquisa também aponta que $33,4 \%$ dos participantes teletrabalham mais de 40 horas semanais. No que diz respeito às variáveis de trabalho, houve pontuações acima da média da escala nos aspectos: importância social do trabalho; controle sobre o trabalho; relacionamento com a chefia; relacionamento no trabalho; suporte social e comprometimento. As análises de correlação demonstraram que os quadros psicopatológicos foram considerados fenômenos relacionados às interações que o trabalhador realiza com a natureza, com a sociedade e consigo mesmo. Os resultados se revelaram, de forma geral, favoráveis ao teletrabalho, e, com exceção de algumas evidências de sintomas maníacos, não foram identificados maiores quadros indicadores de sofrimento psíquico nos teletrabalhadores.
\end{abstract}

Palavras-chave: Saúde mental, Epidemiologia do trabalho, Teletrabalhadores.

The teleworkers epidemiology: impacts of telework in mental health

This study is based on the approach of the epidemiology of work by Codo, Soratto and Vasques-Menezes (2004), and it aims at identifying psychological impacts of telework on the mental health of teleworkers. It is worth noting that mental health was taken as a variable of interest and that it was associated with three relationship dimensions that concerns mental health at work: man and nature, man and society and man with himself. 90 teleworkers answered they survey. The results show that teleworkers work especially in communication and information technology areas. The survey also shows that $33,4 \%$ of the participants telework more than 40 hours per week. The variables Importance of Labor; Worker Control over Work; Relationship with Superiors; Relationship at Work; Social Support and Commitment had scores above scale mid-point. The correlation analysis showed that psychopathological phenomena were related to the interactions that worker holds with nature, with society and themselves. The results, in general, were favorable to telework, and, except for some evidence of manic symptoms, were not identified higher rates indicating psychological distress in teleworkers.

Keywords: Mental Health, Epidemiology of Work, Teleworkers.

$\mathrm{D}$ acordo com Malvezzi (2004), o advento tecnológico da informação contribuiu para que trabalho fosse pensado de maneira diferente, seja por conta das inovações de instrumentais tecnológicos, seja por conta das mais novas formas de contrato e das condições de trabalho. As configurações de trabalho mudam e ainda têm um longo caminho a percorrer em busca da legitimação de suas práticas. Neste passo, delineiam-se formas de trabalho cada vez mais aliadas às tecnologias que permitem maior mobilidade e flexibilidade nos negócios, como o trabalho à distância/teletrabalho. A seu favor, importantes passos: com o objetivo de regulamentar o trabalho realizado em domicílio, a partir da adaptação nas esferas trabalhista e jurídica, foi aprovada, em 15 de dezembro de 2011, a Lei nํㅗ 12.551, que alterou o artigo $6^{0}$ da

1 Instrumento cedido pelo Professor Dr. Wanderley Codo, coordenador do Laboratório de Psicologia do Trabalho, da Universidade de Brasília, e gentilmente enviado pela Msc. Betina Silvestri Miranda. Aos dois, sinceros agradecimentos. Reconhecimento, também, aos colaboradores da SOBRATT, SuperTau e ao Antônio Jorge Moura, por sempre demonstrarem interesse e disposição em ajudar. 
Consolidação das Leis do Trabalho (CLT), em prol da equiparação da subordinação jurídica dos profissionais que trabalham a partir de meios telemáticos e informatizados.

No caso do teletrabalho, o fácil acesso aos computadores, celulares, Internet e outras ferramentas tecnológicas tem permitido que os indivíduos exerçam suas atividades sem a necessidade de ocupar um local específico e determinado às atividades relacionadas a suas tarefas. A rápida disseminação das novas tecnologias de teleinformação e as mudanças nas formas de contrato reformularam elementos significativos dos meios e das condições de trabalho (Malvezzi, 2004). Entretanto, não se deve agir para implementar essas tendências sem antes considerar uma série de implicações referentes à descentralização do locus de trabalho, tais como: a tendência ao isolamento; os conflitos trabalho $\times$ família; a administração do tempo $\times$ tendência a procrastinação; o planejamento e o monitoramento das atividades; os aspectos motivacionais; o sofrimento no trabalho etc.

Os teletrabalhadores, de forma geral, lidam com um contexto de trabalho ainda pouco convencional, abordando tanto as vantagens quanto as dificuldades inerentes à prática do teletrabalho, e ainda precisam levar em consideração as questões referentes à própria saúde física e mental, preocupando-se com os aspectos ergonômicos, fisiológicos, sociais e psicológicos que impactam no desempenho, na produtividade, na realização profissional e na saúde global do indivíduo.

O teletrabalho, portanto, é um terreno fértil para pesquisas sobre trabalho e saúde mental, uma vez que lida com aspectos pouco usuais e estudados do trabalho. Sabe-se que o trabalho influencia todos os aspectos da vida de uma pessoa, pois tem papel ativo na construção da identidade e da vida em sociedade (Malvezzi, 2004). Agregado a isso, o trabalho também se encontra como via potencial de sofrimento, seja de forma objetiva ou subjetiva. De acordo com Codo, Soratto e Vasques-Menezes (2004), o trabalho ajuda a compreender o ser humano e não pode ser desassociado do leque das múltiplas determinações da saúde mental.

O presente estudo objetiva responder à seguinte problemática: quais são os impactos do teletrabalho na saúde mental dos teletrabalhadores? Para tanto, a abordagem escolhida foi a da epidemiologia do trabalho, que analisa a multicausalidade das doenças, associada à ideia de que "o trabalho/atividade aparece como fator de construção da individualidade do sujeito, sendo o elo entre sujeito-sociedade" (Codo, Soratto \& Vasques-Menezes, 2004, p. 289). Assim, além de considerar os aspectos relativos à saúde, a abordagem epidemiológica do trabalho busca investigar a relação do trabalhador com a natureza, com a sociedade e consigo mesmo, perpassando pelas lógicas sociais, econômicas, pessoais e clínicas, numa visão integrada do trabalho.

Aliados à proposta de identificar os impactos psicológicos do teletrabalho na vida dos teletrabalhadores, delineiam-se os objetivos específicos no sentido de identificar os possíveis quadros psicopatológicos decorrentes desta modalidade de trabalho e, por fim, avaliar as relações entre o teletrabalho e a saúde mental dos teletrabalhadores.

\section{Abordagem epidemiológica do trabalho}

É patente, no discurso psicológico, que o homem é um ser social e histórico. Com isso, entende-se que as interações que o indivíduo realiza com o meio ambiente são permeadas por vínculos estabelecidos socialmente. Conforme Codo (1996), o homem é um ser histórico exatamente na medida em que consegue transcender suas próprias ações, ao convertê-las em significado. E o trabalho, para Marx (1996), configura-se na condição de existência do homem, transcende todas as formas de sociedade e existe pautado na necessidade natural de mediação 
entre os homens e a natureza. Para Codo (1989), as relações sociais, principalmente por conta das informações disseminadas pelos meios de comunicação de massa, são baseadas num modo de produção, o capitalista, que determina e transforma a maneira como as pessoas se relacionam com seus pares, com as instituições e com o próprio trabalho. Como consequência desta forma de produção, estabeleceu-se um materialismo social, que faz que o indivíduo produza aquilo que ele não consome e adquira mercadorias que não produziu, reforçando as relações sociais de produção em direção à alienação e à dependência dos bens de consumo para a satisfação das necessidades humanas.

Apoiado na visão marxista, Codo (1989) e colaboradores (Codo \& Soratto, 1999; Codo, Soratto \& Vasques-Menezes, 2004) ressaltam que o homem é o produtor de sua própria existência, ao se relacionar com os outros e com o ambiente ao mesmo tempo em que recebe as múltiplas influências dessas interações. A esta ideia deve-se incluir o trabalho como entidade transformadora e transformada, constantemente, em níveis ambientais, sociais e individuais.

Associada à lógica da epidemiologia geral e com a compreensão de que as doenças teriam relação com a dinâmica da produção capitalista, "a psicopatologia só pode ser decifrada se remetida aos vínculos concretos do homem na vida" (Codo, Soratto \& Vasques-Menezes, 2004, p. 289). É a partir desta conceituação, associada a elementos da epidemiologia geral, que a epidemiologia do trabalho reconhece a natureza histórica e social do processo saúde-doença e objetiva compreender os efeitos gerados pelo trabalho no contexto do modo de produção capitalista.

Segundo Codo (2002), Jacques (2007) e Lima (2003), o estabelecimento do nexo causal entre saúde mental e trabalho não deve recair, somente, sobre a psicopatologia, pois, "o universo em análise não é psicológico, sociológico, econômico, antropológico, é tudo isto ao mesmo tempo" (Codo, 2002, p. 185). Com o objetivo de analisar o campo da saúde mental inserido no contexto de trabalho, Codo (2002) dividiu-o, didaticamente, em três grandes áreas:

- A relação homem-natureza. É estabelecida a partir das possibilidades e formas como a pessoa controla seu ambiente e/ou é controlada por ele, bem como o sentido que o trabalho adquire para o indivíduo e para a sociedade. Em sua metodologia, Codo utiliza as escalas de controle do trabalhador sobre o trabalho, sentimento de rotina, sentido do trabalho e importância social do trabalho para investigar esta dimensão.

- A relação homem-sociedade. O trabalho não ocorre desvinculado de uma sociedade, cuja egrégora determina e transforma as relações sociais. A hierarquia e a divisão do trabalho organizam o cotidiano das pessoas, estabelecendo os vínculos de gênero, o convívio familiar e as possibilidades de vivenciar o afeto, o ócio, o lazer etc. Esta dimensão é analisada à luz das escalas de suporte social, suporte afetivo, relacionamento pessoal (com a chefia e com os colegas) e conflito trabalho $\times$ família.

- A relação do homem consigo mesmo. Esta dimensão é marcada pela atitude do trabalhador frente ao trabalho, bem como pela carga mental exigida por fatores como o tempo e a tarefa em si. As escalas de satisfação, comprometimento e carga mental completam as investigações sobre as variáveis objetivas, subjetivas e transubjetivas que impactam a saúde mental do trabalhador.

Com base nessas informações, cabe dizer que a metodologia proposta pela epidemiologia do trabalho busca aliar estratégias semiclínicas, interdisciplinares e instrumentos de avaliação baseados em escalas psicométricas, que visam à reconstrução da totalidade significativa e ao resgate da história individual e coletiva, partindo da premissa de que o trabalho teria participação determinante, mas não exclusiva, na gênese dos transtornos mentais (Codo, 1988; Codo \& Soratto, 1999; Codo, Soratto, \& Vasques-Menezes, 2004).

Cabe dizer que as apreciações trazidas pela epidemiologia do trabalho às abordagens de estresse, psicodinâmica do trabalho e sócio-histórica trouxeram questionamentos de ordens prática e ideológica que sistematizaram a proposta metodológica deste estudo, uma vez que as 
críticas levantadas sobre a primeira teoria ressaltam certa incongruência entre a visão físicobiológica e a ideia de que o estresse é algo essencialmente negativo e que deve ser combatido. A respeito da abordagem psicodinâmica, além da diferença na problemática teórico-conceitual, evidenciam-se as preocupações exclusivas com a investigação qualitativa e interpretativa dos trabalhadores em detrimento de uma análise do trabalho. Já a teoria sócio-histórica, ainda que compartilhe com os interesses epistemológicos presentes no marxismo e que não privilegie os diagnósticos clínicos, opta, também, exclusivamente por metodologias de investigação qualitativa, como entrevistas, análises documentais, intervenções coletivas etc.

Torna-se, assim, imprescindível considerar as variáveis de percepção do trabalhador, à luz da epidemiologia do trabalho, associando-as aos fatores de saúde mental que se busca investigar. De acordo com Codo, Soratto e Vasques-Menezes (2004), faz-se necessária a compreensão de que o campo da saúde mental no trabalho é permeado por condições objetivas, subjetivas e transubjetivas e exige estratégias de investigação, divididas em três momentos:

- Observação do trabalho. Diz respeito à análise objetiva do trabalho. Neste momento, são realizadas observações diretas, entrevistas e análises de documentos que permitam apreender aspectos da cultura organizacional, da estrutura e do funcionamento, bem como a caracterização do trabalho e cargos objetos da investigação.

- Diagnóstico epidemiológico. Trata-se da análise quantitativa sobre os aspectos subjetivos do trabalho. Esta etapa é composta pela aplicação de inventários de condições de trabalho e saúde mental (chamado de Diagnóstico Integrado do Trabalho - DIT) e objetiva levantar o perfil da categoria analisada.

- Aprofundamento diagnóstico. Realizado por meio de uma metodologia clínica, que visa a analisar estudos de caso e entrevistas com fins de confirmar qualitativamente os dados obtidos na fase anterior, bem como realizar um diagnóstico diferencial.

Objetivando maiores compreensões acerca da saúde mental dos teletrabalhadores, apresentam-se algumas características a respeito do teletrabalho.

\section{Teletrabalho}

O teletrabalho surge como uma das formas que as organizações e as pessoas podem escolher para se adaptar aos contextos de mudança. Em outras palavras, o teletrabalho pode ser interpretado por uma série de desdobramentos rumo a uma maior flexibilidade no que diz respeito ao trabalho e à forma de organizá-lo (ECaTT, 2000).

Em 2012, o teletrabalho encontra-se num movimento de expansão e multiplicação que abrange os mais diversos segmentos de negócios e visa a aliar a inovação tecnológica às dificuldades comumente encontradas na vida dentro das grandes cidades, como a falta de espaço, transporte e segurança. Desta forma, o teletrabalho seria caracterizado pela forma de produção não presencial, que engloba a flexibilidade de tempo, espaço e comunicação, com vistas à competitividade e, ainda, tendo como sua base de sustentação as tecnologias de informação e de comunicação (TICs) (Castells, 2003; Pereira Jr. \& Caetano, 2009; Rosenfield, 2005; Silva, 2009).

Muitos são os tipos de trabalho e de teletrabalhadores que o mundo dos negócios pode abarcar. Há pessoas trabalhando em casa com o consentimento do empregador, há profissionais autônomos que trabalham em casa ou em telecentros e pessoas que complementam suas atividades com trabalhos não presenciais. Alguns pais trabalham em casa por não apresentarem condições de deixar os filhos sozinhos, outras pessoas o fazem pela impossibilidade de se locomover com tranquilidade e em tempo hábil nos grandes centros urbanos. Há 
teletrabalhadores satisfeitos, realizados e bem-sucedidos, assim como profissionais frustrados, solitários, mal pagos e sem reconhecimento (Rosenfield, 2005).

Inúmeras são as combinações de fatores que caracterizam o teletrabalho. Não obstante, é inexistente um conceito único e compartilhado acerca do tema. Neste estudo, optou-se por definir o teletrabalho como uma modalidade de trabalho marcada pela flexibilidade na abrangência de espaço, tempo, aspectos socioeconômicos e culturais, mediada por tecnologias de informação e de comunicação que permitam a expansão das fronteiras e das possibilidades produzidas pelo trabalho convencional.

\section{Impactos do teletrabalho para o indivíduo, a organização e a sociedade: estudos}

De acordo com Mello (2011), há mais de três décadas o teletrabalho tem sido alvo de estudos, principalmente a partir da década de 1990, com a popularização da Internet e das ferramentas dela advindas. A seguir, apresenta-se um breve apanhado sobre as pesquisas que envolveram o teletrabalho no Brasil na última década, em ordem cronológica:

Boonen (2003) analisou as percepções tanto de teletrabalhadores quanto de trabalhadores convencionais acerca do teletrabalho realizado em uma empresa atacadista. Como método de investigação, utilizou questionário e análise descritiva. Em seus resultados, vislumbrou que: o trabalho feito em casa não afeta fortemente a sensação de isolamento; ocorre aumento de carga diária de teletrabalho; há impactos no relacionamento social (sociedade/família); é necessário autocontrole (autodisciplina, administração do tempo, motivação); acontece queda na percepção sobre a valorização do trabalhador (representação social); é preciso buscar autodesenvolvimento; ocorrem estreitamento na comunicação com a empresa e a percepção de que a empresa confia nas decisões tomadas à distância.

Mill (2006) investigou, por meio de questionários e entrevistas semiestruturadas realizadas à distância, a transformação do trabalho do educador em decorrência das mudanças espaço-temporais trazidas pelos processos pedagógicos virtuais. Para tanto, utilizou análises descritivas e de interpretação. Dentre os resultados, destacam-se: a caracterização do educador à distância; a descrição do tutor virtual como um teletrabalhador docente; benefícios e riscos da docência virtual e do teletrabalho; análise da relação entre teletrabalho, tecnologia e relações de gênero; uma proposta metodológica que integra a temática central de sua pesquisa, ou seja, trabalho, tecnologia e educação.

Goulart (2009) publicou detalhes sobre a validação e a implementação do teletrabalho no Serviço Federal de Processamento de Dados, SERPRO. Sua metodologia envolveu ações de gestão, divulgação, elaboração de aparatos legais (termo aditivo de contrato) e mudanças na infraestrutura (física e de redes). As análises descritivas revelaram que a mudança foi executada por meio de transformações em aspectos de cultura e estrutura organizacionais e apresentou resultados concernentes aos índices de produtividade, economia de recursos para a empresa e para o teletrabalhador, qualidade de vida, integração familiar, conforto físico, estresse, índices de conformidade profissional, integração profissional, administração do tempo, adaptação ao teletrabalho e infraestrutura.

Mello (2011) utilizou o método quali-quanti, alternando-se em estudos de caso e questionários, para investigar as forças propulsoras, as restritivas e as contribuições reconhecidas pelo uso do teletrabalho nas empresas de call center e contact center. Além das análises descritivas, realizou análises multivariadas de agrupamento e, ainda, análises de correspondência. Identificou que o teletrabalho é adotado pelas empresas pesquisadas por 
motivos de redução de custos, aumento de produtividade, melhora no atendimento ao cliente, qualidade de vida e inclusão social e digital, inclusive, de pessoas com deficiência. Caracterizou as forças propulsoras e restritivas como de ordem social, econômica, legal e comportamental e, ainda, listou os ganhos obtidos pelas empresas e pelos teletrabalhadores.

A partir do apanhado teórico até aqui apresentado, pode-se perceber que o teletrabalho é abordado, principalmente, pelas teorias da administração. Os fenômenos psíquicos advindos dessa forma de trabalho foram, até agora, hipotetizados, mas não pesquisados. Assim, o presente estudo baseou-se na necessidade de investigar os impactos do teletrabalho na saúde mental dos teletrabalhadores, uma vez que as pesquisas apresentadas não agregaram ou aprofundaram-se nesta questão.

\section{Método}

\section{Delineamento de pesquisa}

A pesquisa é de caráter descritivo, quantitativo e de delineamento correlacional (survey). Vale ressaltar que a saúde mental foi tomada como variável de interesse e que a pesquisa contemplou apenas a etapa de diagnóstico epidemiológico, dada a impossibilidade de realizar as etapas de observação no local de trabalho e de entrevistas clínicas, já que os participantes residem em diversas partes do Brasil.

\section{Critérios para a seleção de participantes e coleta de dados}

O critério para a participação na pesquisa era estar exercendo atividade "teletrabalhável", seja de forma integral, autônoma ou complementadora. Para a seleção dos participantes, primeiramente, foram utilizados os mecanismos de busca em diversas redes sociais à procura de perfis de usuários que contivessem palavras-chave relacionadas ao teletrabalho. Após a análise do perfil da população nas redes sociais, os indivíduos eram convidados a participar da entrevista por intermédio de um e-mail que continha mais explicações acerca da pesquisa, o Termo de Consentimento Livre e Esclarecido e um link para o questionário, que deveria ser acessado e respondido pelo participante. A divulgação inicial da pesquisa foi realizada em redes sociais, como Orkut, Facebook, Linkedin e Twitter, com um perfil elaborado exclusivamente para esta finalidade. Desta forma, a amostra caracterizou-se por ser não probabilística e de conveniência.

A partir da divulgação, houve, por iniciativa de participantes, o noticiamento e a disponibilização do questionário em outros dois veículos de comunicação: o site www.supertau.com (rede social com foco em oportunidades de negócios), que, entre $1^{\mathrm{o}}$ de setembro e 30 de novembro de 2011, disponibilizou a pesquisa para seus mais de 4.600 usuários; e o site www.sejabeminformado.com.br (de notícias diárias) que, em 12 de setembro de 2011, noticiou e compartilhou o link para o questionário. O período de coleta de dados se estendeu de agosto a novembro de 2011, e 1.253 e-mails foram enviados.

\section{Participantes}

Responderam à pesquisa 90 indivíduos. Houve uma leve predominância de teletrabalhadores do sexo masculino (55,6\%). A maior concentração etária foi entre 30 e 39 anos (30,0\%), distribuídos em 14 estados brasileiros, com destaque para São Paulo (responsável 
por $44,4 \%$ da amostra), seguido pelo Distrito Federal (12,2\%). Exatos 40,0\% possuem pósgraduação ou mais. 55,6\% dos participantes são casados, e 59,9\% possuem um ou mais filhos.

A maioria dos pesquisados $(51,1 \%)$ teletrabalha entre um e cinco anos. Foram encontradas treze áreas de atividades em teletrabalho, com destaque para comunicação/jornalismo e tecnologia da informação, com 33,3\% e 17,8\%, respectivamente. A categoria de teletrabalho que prevalece é o autônomo (45,6\%), seguido pelo integral $(27,8 \%$ da amostra). 33,3\% dos pesquisados alegam teletrabalhar entre 30 e 40 horas semanais. Contudo, também é significativa a parcela de indivíduos que exercem teletrabalho em mais de 40 horas por semana $(26,7 \%)$. Da população total, 75,6\% também cumprem carga horária presencial. Destes, $28,1 \%$ trabalham presencialmente por, até, cinco horas por semana. Dentre os pesquisados, $20 \%$ exercem, ainda, outro tipo de atividade remunerada.

\section{Instrumento de coleta: inventário de diagnóstico integrado do trabalho - DIT}

O DIT é um protocolo de investigação que contém 54 questões referentes às percepções do trabalho, 86 itens relativos ao sofrimento psíquico/alcoolismo e, ainda, 12 itens concernentes ao levantamento de dados demográficos, funcionais e/ou perfil dos participantes. Vale destacar que algumas questões que abordam o sofrimento psíquico pertencem a mais de um fator. Desta forma, o DIT totaliza 142 questões, distribuídas em 14 fatores de trabalho e 11 de saúde, com alfas variando de 0,60 a 0,85 (Miranda, 2002; Oliveira, 2009): relacionamento pessoal com a chefia, relacionamento profissional com a chefia, sentido do trabalho, importância social do trabalho, controle do trabalhador sobre o trabalho, sentimento de rotina, suporte social, suporte afetivo, relacionamento no trabalho, satisfação, comprometimento, conflito trabalho $\times$ família, carga mental relacionada à tarefa, carga mental relacionada ao tempo, depressão, mania, desvio psicopático, obsessão, paranoia, paranoia de alto risco, esquizofrenia, histeria conversiva, histeria sexual, histeria afetiva e alcoolismo.

Cabe dizer que o instrumento foi digitalizado para ser aplicado on-line, dada a natureza descentralizada do teletrabalho e a possibilidade de dar uma abrangência nacional à população pesquisada. A escala possui amplitude de 7 pontos, em que 1 significa "discordo totalmente" e 7, "concordo totalmente".

\section{Procedimentos de análise de dados}

A identificação das percepções dos participantes acerca das dimensões do trabalho e da saúde mental se deu pelas análises descritivas das medidas de tendência central e de variação. Médias entre 1 e 2,9 foram consideradas como pouco endosso ou aparição dos fenômenos estudados; médias entre 3 e 4,9, endosso mediano; e entre 5 e 7, elevadas. Os desvios-padrão a partir de 1,2 foram considerados altos.

Para conseguir verificar a relação entre as dimensões do teletrabalho e a saúde mental, realizou-se a análise de correlação de Pearson entre as variáveis das dimensões do trabalho, demográficas e de saúde mental. O programa utilizado foi o SPSSwin20.

\section{Resultados}

São exibidos a seguir os resultados descritivos e, posteriormente, as correlações. 


\section{Análises descritivas}

A Tabela 1 aborda os resultados da análise descritiva das variáveis em saúde mental. Pode-se verificar que nenhuma média ficou acima do ponto mediano da escala. A variável mania $(3,55)$ foi a que mais se aproximou da média.

Tabela 1: Descritivas das variáveis de saúde mental

\begin{tabular}{|c|c|c|c|}
\hline Variáveis & Média & Desvio-padrão & Moda \\
\hline Mania & 3,55 & 1,01 & 2 \\
\hline Histeria conversiva & 3,03 & 1,60 & $2^{*}$ \\
\hline Paranoia & 2,74 & 0,93 & $1^{*}$ \\
\hline Histeria afetiva & 2,63 & 1,27 & 2 \\
\hline Desvio psicopático & 2,55 & 1,05 & 2 \\
\hline Depressão & 2,47 & 1,34 & $1 *$ \\
\hline Obsessão & 2,46 & 1,16 & 1 \\
\hline Esquizofrenia & 2,38 & 1,13 & 1 \\
\hline Histeria sexual & 1,87 & 1,10 & 1 \\
\hline Alcoolismo & 1,67 & 1,10 & 2,72 \\
\hline Paranoia alto risco & 1,41 & & 2 \\
\hline
\end{tabular}

*Modas múltiplas. O menor valor foi exibido.

Na Tabela 2, são apresentadas as percepções das três dimensões em saúde, segundo a epidemiologia do trabalho - relação homem-natureza, relação homem-sociedade e relação do homem consigo mesmo -, com o intuito de descrever a percepção do teletrabalhador sobre seu trabalho.

Tabela 2: Descritivas das variáveis da relação homem-natureza

\begin{tabular}{|c|c|c|c|}
\hline Variáveis & Média & Desvio-padrão & Moda \\
\hline \multicolumn{4}{|l|}{ Relação homem-natureza } \\
\hline Importância social do trabalho & 5,79 & 1,39 & 7 \\
\hline Controle do trabalhador sobre o trabalho & 4,99 & 1,01 & 5 \\
\hline Sentido do trabalho & 3,09 & 0,89 & 3 \\
\hline Rotina & 3,09 & 1,40 & 2 \\
\hline \multicolumn{4}{|l|}{ Relação homem-sociedade } \\
\hline Relacionamento profissional com a chefia & 5,14 & 1,56 & 7 \\
\hline Relacionamento pessoal com a chefia & 4,94 & 1,73 & 7 \\
\hline Relacionamento no trabalho & 4,92 & 1,45 & $6^{*}$ \\
\hline Suporte social & 4,54 & 1,44 & 7 \\
\hline Suporte afetivo & 3,43 & 1,84 & 1 \\
\hline Conflito trabalho x família & 3,34 & 1,71 & 3 \\
\hline \multicolumn{4}{|l|}{ Relação do homem consigo mesmo } \\
\hline Comprometimento & 5,44 & 1,43 & 7 \\
\hline Carga mental (tempo) & 3,68 & 1,44 & $3 *$ \\
\hline Satisfação & 3,60 & 0,95 & 3 \\
\hline Carga mental (tarefa) & 3,49 & 1,31 & 3 \\
\hline
\end{tabular}

* Modas múltiplas. O menor valor foi exibido. 
A dimensão homem-natureza apresentou médias consideradas altas nos fatores importância social do trabalho $(5,79)$ e controle do trabalhador sobre o trabalho $(4,99)$. Na dimensão homem-sociedade, os dados indicam que quatro, dos seis fatores, têm escores acima do ponto médio. Contudo, todos os desvios-padrão foram altos, acima de 1,40 , o que revela grande variação das percepções dos teletrabalhadores.

A dimensão da relação homem consigo mesmo teve um único fator com média acima do ponto médio: comprometimento $(5,44)$, ao passo que a percepção de satisfação apresentou a menor variação entre as respostas $(s=0,95)$, porém a média $(3,60)$ manteve-se abaixo do ponto médio da escala.

\section{Análises de correlação}

Os dados apresentados na Tabela 3 demonstram as correlações obtidas entre as variáveis das três dimensões em saúde mental e trabalho e os quadros psicopatológicos investigados.

Tabela 3: Correlações entre as variáveis individuais, sociais, de trabalho e de saúde mental

\begin{tabular}{|c|c|c|c|c|c|c|c|c|c|c|c|}
\hline Fatores & 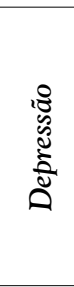 & 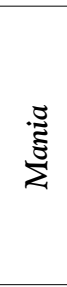 & 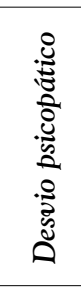 & 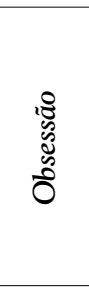 & 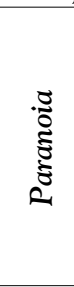 & 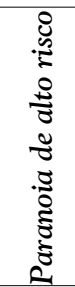 & 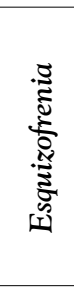 & 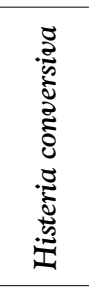 & 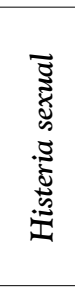 & 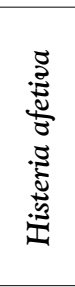 & 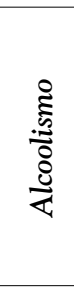 \\
\hline $\begin{array}{l}\text { Controle sobre o } \\
\text { trabalho }\end{array}$ &,- 14 & ,05 &,- 11 &,- 07 &,- 07 &,- 18 &,- 01 &,- 05 &,- 13 & ,09 &,- 17 \\
\hline $\begin{array}{l}\text { Sentimento de } \\
\text { rotina }\end{array}$ & $41^{* *}$ &, 12 &, $33^{* *}$ &, $22^{*}$ &, $34^{* *}$ & $26^{*}$ & ,18 & $31^{* *}$ & $23^{*}$ & ,18 & $23^{*}$ \\
\hline $\begin{array}{l}\text { Sentido do } \\
\text { trabalho }\end{array}$ &, $50^{* *}$ &, $23^{*}$ & $45^{* *}$ &, $37^{* * *}$ &, $32^{* * *}$ &, $41^{* *}$ &, $34^{* *}$ &, $33^{* * *}$ &, $40^{* *}$ & , 29" &, $35^{* *}$ \\
\hline Importância social &,$- 40^{* * *}$ &,- 03 &,$- 29^{* * *}$ &,$- 27^{*}$ &,- 16 &,$- 22^{*}$ &,$- 25^{*}$ &,$- 26^{*}$ & $-39^{* *}$ &,- 17 &,$- 26^{*}$ \\
\hline Suporte social &,$- 37^{* * *}$ &,- 07 &,$- 35^{* *}$ &,$- 38^{* * *}$ &,$- 28^{* * *}$ &,- 19 &,- 17 &,$- 32^{* *}$ &,$- 32^{* * 4}$ & $-34^{* *}$ &,- 02 \\
\hline Suporte afetivo &, $69^{* *}$ &, $48^{*+4}$ &, $78^{* *}$ &, $69^{* * *}$ &, $64^{* * *}$ &, $35^{* *}$ &, $61^{* * *}$ &, $52^{* * *}$ &, $53^{* * *}$ &, $49^{* * *}$ &, $27^{* * *}$ \\
\hline $\begin{array}{l}\text { Rel. pessoal com } \\
\text { chefia }\end{array}$ &,- 08 & 01 &,- 03 & ,02 & ,16 &,- 08 & ,01 & , 07 &,- 08 & ,16 & $-38^{* *}$ \\
\hline $\begin{array}{l}\text { Rel. profissional } \\
\text { com chefia }\end{array}$ &,- 02 & 11 &,- 05 & ,02 & ,19 &,- 08 & ,04 &, 10 &,- 06 & ,12 &,- 21 \\
\hline $\begin{array}{l}\text { Relacionamento } \\
\text { no trabalho }\end{array}$ &,- 13 &,- 12 &,$- 21^{*}$ &,- 14 &,- 20 &,$- 24^{*}$ &,- 11 &,- 04 & ,02 &,- 08 &,$- 31^{* *}$ \\
\hline $\begin{array}{l}\text { Conflito trabalho } \\
\text { família }\end{array}$ &, $55^{* *}$ &, $36^{* * *}$ & $45^{* *}$ &, $48^{* * *}$ &, $35^{* *}$ & , 21" &, $41^{* * n}$ &, $57^{* * *}$ &, $47^{* * *}$ & , 48 &,- 01 \\
\hline Satisfação &, $73^{* *}$ &, $46^{* * 4}$ &, $67^{* *}$ &, $58^{* *}$ & $60^{* * *}$ &, $32^{* *}$ &, $45^{* *}$ &, $54^{* * *}$ &, $58^{* * *}$ &, $50^{* * *}$ & ,18 \\
\hline Comprometimento &,$- 35^{* *}$ &,- 05 & $-27^{*}$ &,$- 23^{*}$ &,- 01 &,- 13 &,$- 27^{*}$ &,$- 22^{*}$ &,$- 36^{* * 4}$ &,- 03 &,- 16 \\
\hline $\begin{array}{l}\text { Carga mental, } \\
\text { tarefa }\end{array}$ &, $51^{* *}$ &, $48^{* *}$ & $49^{* *}$ &, $60^{* * *}$ &, $38^{* *}$ &, $38^{* *}$ &, $56^{* *}$ &, $52^{* *}$ & $49^{* *}$ &, $51^{* *}$ &, 19 \\
\hline $\begin{array}{l}\text { Carga mental, } \\
\text { tempo }\end{array}$ &, $59^{* *}$ & ,49.is &, $59^{* *}$ & $62^{* *}$ & $43^{* *}$ &, $39^{* *}$ & $65^{* *}$ &, $55^{* *}$ &, $50^{* *}$ &, $55^{* *}$ & ,16 \\
\hline Sexo & ,10 & ,19 & ,07 & , 14 & ,12 & ,11 & ,11 &, $26^{*}$ & ,15 & ,01 & ,06 \\
\hline Idade &,$- 22^{*}$ & $-25^{*}$ &,$- 25^{*}$ &,$- 36^{* * *}$ &,- 07 &,$- 26^{*}$ &,$- 33^{* * *}$ &,$- 24^{*}$ &,- 17 &,$- 37^{* *}$ &,- 05 \\
\hline $\begin{array}{l}\text { Tempo de } \\
\text { teletrabalho }\end{array}$ &,- 19 &,- 05 &,$- 22^{*}$ &,$- 26^{*}$ &,- 08 &,- 03 &,$- 22^{*}$ &,$- 22^{*}$ &,- 15 & $-26^{*}$ & ,04 \\
\hline $\begin{array}{l}\text { Carga semanal de } \\
\text { teletrabalho }\end{array}$ &,- 15 &,- 01 &,- 11 &,- 17 &,- 11 &,- 02 &,- 03 & ,01 &,- 06 &,- 10 & ,06 \\
\hline $\begin{array}{l}\text { Carga horária } \\
\text { presencial }\end{array}$ & ,18 &, 16 &, 12 &, 15 & ,20 &,- 15 & ,23 &,- 01 & ,09 &, $29^{*}$ &,- 05 \\
\hline
\end{tabular}

No que diz respeito às variáveis da relação homem-natureza, verificou-se, na Tabela 3, que a variável sentido do trabalho foi a que mais apresentou correlações significativas com os 
aspectos de sofrimento psíquico. O fator importância social do trabalho correlacionou-se negativamente com todas as variáveis de saúde mental, revelando que, quanto maior é a percepção da importância social do trabalho, menor é a manifestação dos sintomas psicopatológicos. Contudo, a correlação só foi mais forte quando associada à variável depressão $(\mathrm{r}=-0,40 ; \mathrm{p}<0,01)$.

Conforme os resultados da Tabela 3, a análise correlacional das variáveis da relação homem-sociedade e de saúde mental indica uma correlação negativa entre o suporte social e todos os quadros de saúde mental. A percepção de suporte afetivo também se correlacionou com todos os onze fatores de saúde mental.

Ainda de acordo com a Tabela 3, tanto o relacionamento pessoal com a chefia $(\mathrm{r}=$ $-0,38 ; \mathrm{p}<0,01)$ quanto o relacionamento no trabalho $(\mathrm{r}=-0,31 ; \mathrm{p}<0,01)$ evidenciam correlações negativas e significativas apenas com o alcoolismo. Já as correlações do fator conflito trabalho $\times$ família apresentaram correlações com nove fatores de saúde mental.

Os resultados referentes às correlações entre as variáveis da relação do homem consigo mesmo e as variáveis de saúde mental do DIT revelam que esta dimensão foi a que mais estabeleceu relações com as variáveis que indicam sofrimento psíquico. A satisfação no trabalho foi correlacionada a dez variáveis de saúde mental, apenas com a exceção do alcoolismo. No que diz respeito ao comprometimento no trabalho, mesmo as correlações mais significativas apresentaram-se de forma fraca, negativa e estão relacionadas às variáveis histeria sexual e depressão $(r=-0,36 ; p<0,01 ; r=-0,35 ; p<0,01$, respectivamente). Esses dados revelam que, quanto maior é o comprometimento, mais afastados os indivíduos permanecem das psicopatologias relacionadas ao trabalho.

As correlações entre as informações demográfico-funcionais relevantes e as variáveis de saúde mental indicam que os indivíduos com mais idade encontram-se menos suscetíveis a vivenciar os sintomas que caracterizam o sofrimento psíquico.

É interessante observar que os fatores tempo no teletrabalho e carga horária presencial apresentaram algumas fracas correlações com os aspectos de saúde mental. Percebe-se que tanto o tempo no teletrabalho quanto a carga horária de teletrabalho atuam positivamente no sentido de melhorar a saúde mental dos participantes, fato que pode ser indicado por meio das correlações negativas entre as variáveis analisadas, ou seja, quanto maior é o tempo dedicado ao teletrabalho, menor é o sofrimento psíquico.

\section{Discussão}

Primeiramente, são discutidos os resultados obtidos junto às análises descritivas das variáveis demográfico-funcionais e das dimensões em saúde mental e trabalho. Em seguida, com base nas análises de correlação, são discutidos aspectos acerca dos impactos do teletrabalho na saúde mental dos teletrabalhadores.

\section{Análises descritivas}

A caracterização demográfica dos teletrabalhadores esteve em consonância com os resultados apontados por Pinto (2003), que confirmam a predominância de teletrabalhadores do sexo masculino, pertencentes à faixa que vai dos 30 aos 49 anos de idade. A maior parcela dos teletrabalhadores pesquisados encontra-se em nível de pós-graduação.

No que diz respeito à região geográfica, os estudos de Barros (2007) e Macaciel e Ferraz (2004) corroboram que o estado de São Paulo é responsável pela maior representatividade do 
número de teletrabalhadores em atividade no Brasil. Uma pesquisa divulgada pela IBM (2010) aponta que São Paulo é a sexta cidade com o pior trânsito dentre as vinte pesquisadas ao redor do mundo. O tempo gasto com os deslocamentos casa-trabalho, bem como os riscos à saúde física e psicológica advindos dos problemas de tráfego nos grandes centros urbanos, atuam como incentivo ao teletrabalho.

Quanto à situação familiar, a maioria dos teletrabalhadores é casada e/ou possui filhos, assim como nos resultados de Barros (2007). Essas informações permitem inferir que os participantes do presente estudo enquadram-se no perfil populacional típico das pesquisas sobre teletrabalho.

A caracterização funcional dos teletrabalhadores aponta que, dentre as categorias de teletrabalho, evidenciou-se o teletrabalho autônomo, conforme definido por Qvortrup (1992, citado em Castells, 1999). Castells (1999) afirma que tanto a categoria autônoma quanto a complementadora vêm assumindo parcelas cada vez mais significativas nas opções dos teletrabalhadores. $\mathrm{O}$ presente estudo verificou, contudo, que a categoria integral superou em $1,1 \%$ o teletrabalho complementador. Mesmo que pequena, a diferença pode revelar algum crescimento dos vínculos integrais em teletrabalho. É possível aferir que as três categorias de teletrabalho dão margem a inúmeras possibilidades de atuação profissional.

Grande parte dos pesquisados teletrabalha entre um e dez anos. Esses dados são similares aos apresentados por Nohara, Acevedo, Ribeiro e Silva (2010), nos quais o tempo de teletrabalho variou entre dois e onze anos.

Verifica-se que quatro grandes áreas se destacam no teletrabalho: comunicação/jornalismo, tecnologia da informação, vendas/serviços e educação. A docência é a área mais escolhida pelos teletrabalhadores que desempenham, também, o trabalho convencional. Este fato vem ao encontro dos resultados apontados por Mill (2006), que afirma que a maioria dos teletrabalhadores da área de educação acumula algum tipo de trabalho in loco, como a docência presencial.

Os resultados demonstram, ainda, a elevada quantidade de indivíduos que dedicam mais de 40 horas semanais a suas atividades (33,4\% dos participantes). Conforme Pinto (2003), o teletrabalho permite não só a flexibilização da jornada de trabalho, mas, também, a possibilidade de se dedicar mais horas às atividades profissionais, pois, geralmente, não há um controle rígido no que diz respeito à carga horária. Os estudos de Barros (2007), Nohara et al. (2010) e Pinto (2003) indicam que uma das características marcantes do teletrabalho é, justamente, o aumento das horas gastas com as atividades, muito por conta da falta de parâmetros físicos e temporais, algo inerente ao teletrabalho. Consequentemente, os teletrabalhadores passam a vivenciar problemas de administração do tempo e de priorização de tarefas. A flexibilidade atribuída ao teletrabalho é apontada como paradoxal, pois, mesmo com todas essas limitações, os teletrabalhadores têm apresentado, por exemplo, queda nos níveis de estresse relacionada à redução do tempo e do custo dos deslocamentos entre a casa e o trabalho. Contudo, conforme indicado por Nohara et al. (2010), o estresse ainda é percebido em virtude das comunicações e/ou cobranças por parte da chefia.

No que diz respeito às relações homem-natureza, as percepções dos teletrabalhadores são mais acentuadas no que diz respeito a sua própria ação sobre a natureza, seja em aspectos de controle sobre o trabalho, ou mesmo na representação do valor social que ele tem. Talvez o sentido do trabalho e as impressões sobre como suas formas de realização influenciam na rotina não tenham sido relevantemente notados, ainda por conta das relações que os modos de produção capitalista engendram, mas, também, em virtude das transformações nos processos, meios e relações de trabalho marcadas pelas TICs. Conforme Codo (1996), essas transformações exigem, cada vez mais, que a subjetividade do trabalhador abarque o envolvimento com os processos de trabalho, e não mais, simplesmente, com a tarefa 
desconectada dos nexos entre o esforço pessoal e as consequências gerais da realização de suas atividades.

As relações sociais estabelecidas pelo homem são muito diversas. No caso dos teletrabalhadores, não é diferente. As variáveis da relação homem-sociedade revelaram variações nas percepções dos participantes. No geral, os teletrabalhadores avaliaram positivamente os relacionamentos estabelecidos no trabalho e sociais, com destaque para os relacionamentos (pessoal e profissional) com a chefia. Esses dados diferem, por exemplo, daqueles obtidos junto a auditores fiscais, que revelaram altos índices de problemas no relacionamento com a chefia (Kitagawa, 2005). Rosenfield (2005) ressalta que o teletrabalho, bem como a flexibilidade que lhe é atribuída, possibilita uma percepção diferenciada acerca da autonomia dos teletrabalhadores, uma vez que as relações de trabalho e a comunicação horizontal minimizam o controle hierárquico. Além disso, as variáveis de suporte afetivo e conflito trabalho $\times$ família foram percebidas de modo parecido, com médias abaixo de 3,5, mas com altos desvios-padrão, fato que sugere algum problema.

No que diz respeito à relação do homem consigo mesmo, verificam-se altos padrões de comprometimento dos teletrabalhadores, assim como foi observado com professores nos estudos de Ferreira (2005) e de Gambeta e Silva (2007). Já a satisfação obteve uma pontuação mediana, com baixa variação das respostas. Outro aspecto que merece ser evidenciado é a percepção dos teletrabalhadores de que a pressão sobre o tempo e os prazos sobrecarregam mais do que a carga mental relacionada à tarefa em si. O excesso de horas dedicadas ao teletrabalho, bem como possíveis problemas na administração do tempo, podem reforçar essas percepções, ao passo que a autodisciplina, a motivação e a administração eficaz do tempo de trabalho são algumas características essenciais do perfil do teletrabalhador (Boonen, 2003).

Com relação à saúde mental em teletrabalho, ficou evidenciado que os sintomas mais presentes são os maníacos. Miranda (2002, p. 67) ilustra que, em casos mais graves, os indivíduos "podem apresentar uma atividade excessiva sem sentido e fala acelerada, e podem ter alucinações e/ou delírios de grandeza". Contudo, os resultados obtidos a partir da escala de mania revelam sintomas situados abaixo do ponto médio, ou seja, ainda que mais maníacos, os teletrabalhadores não apresentam índices preocupantes de psicopatologias, ao contrário do que revelam Kitagawa (2005), que encontrou predominância de sintomas obsessivos em auditores fiscais, e Codo (2002), que informou que o DIT identificou a síndrome do trabalho vazio entre bancários, a paranoia entre digitadores, histeria em trabalhadores de creches e burnout em educadores.

\section{Correlações}

Os resultados das análises de correlação das variáveis homem-natureza indicaram que o sentido do trabalho estabelece vasta relação com as variáveis de saúde mental, principalmente com a depressão. Porém se verifica que os teletrabalhadores pesquisados apresentaram uma apropriação mediana do sentido do trabalho e, também, não exibiram índices significativos de depressão. Mesmo assim, é importante valer-se do alerta de Estrada (2010), ao lembrar que a diminuição das relações interpessoais, problemas na comunicação e a dependência tecnológica podem acarretar depressão. Codo (2002), numa visão mais ampla, complementa que o processo de divisão do trabalho pode dificultar ou, até mesmo, bloquear o significado do trabalho. Assim, uma vez estabelecida a correlação positiva entre o sentido e as variáveis de saúde mental, reforça-se o argumento da epidemiologia do trabalho de que as atividades realizadas pelos seres humanos, geradoras de significados, são fontes potenciais tanto de prazer quanto de sofrimento psíquico. Desta forma, para evitar problemas, há que se investir na importância e no sentido do trabalho. 
No geral, percebe-se que, quando se fala nas relações entre homem e natureza, tanto o sentido do trabalho quanto o sentimento de rotina atuam de forma a diminuir a saúde mental. É necessário ressaltar que os discursos e práticas organizacionais devem fazer parte do processo de constantes transformações do sentido do trabalho e, também, da identidade do teletrabalhador. Conforme ilustra Costa (2003, p. 55): "É o caráter aberto, indeterminado, o deslizamento inevitável na construção de sentidos que abre as possibilidades de invenção, de autonomia, de (re)criação". No que tange a rotina, as inúmeras possibilidades pelas quais podem se configurar as atividades em teletrabalho fazem que seja quase impossível impor um ritmo habitual de atividades, como no caso dos profissionais que atuam em ambientes disponibilizados pelos clientes, daqueles que realizam trabalhos por demanda ou, ainda, dos teletrabalhadores que fazem parte de equipes com membros em diversos países, os quais, muitas vezes, precisam romper as barreiras de fuso horário para trabalhar. Por outro lado, as variáveis controle do trabalhador sobre o trabalho e importância social mostraram-se relevantes no sentido de minimizar o sofrimento psíquico, bem como de reforçar o sentimento de autonomia e de valor social do trabalho.

As correlações obtidas a partir das relações homem-sociedade revelam que pessoas com a saúde mental comprometida tendem a apresentar dificuldades nos relacionamentos pessoais e profissionais, como no caso do conflito trabalho $\times$ família, que estabelece forte relação com o sofrimento psíquico. Por outro lado, quanto maior é o suporte social e melhores são os níveis de relacionamentos, mais saudável é o indivíduo. Os teletrabalhadores pesquisados apontam percepções positivas acerca dos relacionamentos estabelecidos no trabalho, com as chefias e sociais, especialmente no sentido de minimizar as ligações com o alcoolismo. Oliveira (2009) cita uma série de autores que evidenciam que o suporte social está positivamente relacionado com o bem-estar e, ainda, ajuda a minimizar os efeitos do conflito trabalho $\times$ família. No presente estudo, esse conflito, juntamente com o suporte afetivo, aparece numa correlação com a saúde mental que indica maior sofrimento psíquico. Em sua pesquisa sobre o conflito trabalho $\times$ família no contexto de teletrabalho, Smaha (2009) associa o fenômeno às dificuldades encontradas na interação familiar, bem como na separação do tempo de trabalho e não trabalho. É necessário, então, que as famílias e os profissionais envolvidos redefinam as fronteiras do trabalho, para que as famílias transformem sua convivência a partir desse novo contexto laboral (Costa, 2003).

A relação do homem consigo mesmo é a que mais apresenta correlações com as variáveis de saúde mental. Os aspectos de satisfação, comprometimento e carga mental refletem as atitudes do trabalhador frente ao trabalho e, segundo Codo (2002), devem ser olhados como sínteses subjetivas do processo multideterminado que é a saúde mental. As análises de correlação apontam que, quando o sofrimento psíquico está presente, ocorre queda no comprometimento do trabalhador. O contrário também é válido: altos níveis de comprometimento reduzem os impactos das psicopatologias, principalmente nos casos de depressão e histeria sexual. Conforme Alves (2008), sem comprometimento, o controle e a organização do trabalho não ocorreriam. Outro ponto de reflexão interessante precisa ser levantado: a sobrecarga de tempo e de atividades em teletrabalho, bem como os níveis de satisfação do teletrabalhador, estão intimamente relacionados com todos os quadros psicopatológicos abordados na pesquisa. Essa relação ocorre de maneira tal, que teletrabalhadores mais satisfeitos, por exemplo, tendem a apresentar maior sofrimento psíquico. Pode-se supor que teletrabalhadores mais satisfeitos envolvem-se mais com o trabalho, isolando-se do convívio social e da busca pelo aprimoramento em outras atividades geradoras de significados, tão importantes quanto o trabalho na construção da subjetividade de um indivíduo saudável. Vale ressaltar a importância de se pesquisar mais a fundo as formas pelas quais a satisfação relaciona-se com os fatores objetivos do teletrabalho, bem como com os aspectos subjetivos intrínsecos aos teletrabalhadores, uma vez que a literatura acerca da satisfação vai na contramão dos dados obtidos. 
Dentre os dados demográficos, a idade é um fator que reduz a incidência de transtornos mentais. De acordo com Ferreira (2005), a coleta de dados demográficos e funcionais é imprescindível, pois complementa o quadro a ser investigado. Características como sexo, idade e filhos, por exemplo, transpõem aquilo que é observado sobre as condições organizacionais e não podem ser desconsideradas dos fatores que interagem na gênese das psicopatologias. $O$ presente estudo revela que, no teletrabalho, mulheres apresentam maiores possibilidades de desenvolver histeria conversiva. Segundo Nasio (1991), a histeria é marcada por um estado de constante insatisfação, sendo manifestada, predominantemente, em mulheres. Percebe-se, também, que a histeria afetiva foi mais evidenciada nos casos de teletrabalhadores que passam muitas horas a desenvolver trabalhos presenciais. A saber, dentre os teletrabalhadores pesquisados, 18,0\% realizam atividades de forma presencial por mais de 20 horas semanais.

A caracterização funcional dos participantes indica grande número de teletrabalhadores que possuem outros vínculos de trabalho $(20,0 \%)$, fato que pode ser impulsionado pela necessidade de realização de horas extras para complementação de renda. No que diz respeito aos aspectos que envolvem a saúde mental, os dados revelaram que o trabalho presencial estabelece uma relação positiva com o sofrimento psíquico, ao contrário do tempo e da carga horária dedicados ao teletrabalho, que promovem a saúde mental, ou, ao menos, não a pioram. Apesar de não estarem explícitos os motivos pelos quais o trabalho presencial apresenta maiores condições de fazer surgirem os quadros psicopatológicos, é clara a necessidade de investigação desse fenômeno, com vistas a intervir em prol da saúde do trabalhador convencional, bem como impulsionar a adoção do modelo de teletrabalho pelos indivíduos e as organizações.

Em suma, cabe ressaltar que todos os objetivos da pesquisa foram alcançados e com alguns resultados inesperados, positivos ao teletrabalho, no que diz respeito à saúde mental. $\mathrm{Na}$ intenção de realizar uma intervenção e diminuir o sofrimento psíquico dos teletrabalhadores, os quadros psicopatológicos não podem ser abordados como fenômenos isolados das interações que o indivíduo realiza com a natureza, consigo mesmo e com a sociedade. O presente estudo permitiu identificar, por exemplo, que a mania também está significativamente associada a fatores relacionados ao trabalho nas três dimensões: sentido do trabalho, suporte afetivo, conflito trabalho $\times$ família, satisfação e carga mental (relacionada à tarefa e ao tempo). As demais psicopatologias também apresentam, cada qual, sua relação com aspectos objetivos e subjetivos do trabalho, principalmente no que diz respeito aos fatores da relação homemsociedade. Uma vez conhecida essa interação, delineia-se a possibilidade de trabalhar a transformação, de forma prática, dos fatores que promovem o sofrimento psíquico.

\section{Considerações finais}

As transformações nos contextos de trabalho advindas do teletrabalho suscitaram questionamentos acerca da saúde mental dos profissionais que aderiram a esta modalidade. Essa análise se fez presente para despertar o interesse e a viabilização do teletrabalho para as mais diversas profissões, uma vez conhecidos seus riscos e vantagens. O objetivo geral foi identificar os impactos psicológicos do teletrabalho na saúde mental dos teletrabalhadores. Para tanto, foi necessário medir, a partir do contexto de trabalho, as relações estabelecidas pelo homem com a natureza, com a sociedade e consigo mesmo, pela aplicação do Diagnóstico Integrado do Trabalho (DIT), que, também, avalia quadros psicopatológicos associados ao trabalho.

O presente estudo forneceu informações importantes, tanto acadêmicas quanto gerenciais. A contribuição acadêmica foi reconhecer, mais uma vez, que o trabalho também é fonte potencial de sofrimento psíquico e, além disso, relacionar o teletrabalho à diminuição de

\section{6}


problemas em saúde mental. Vale ressaltar que, no Brasil, não há precedentes de pesquisas dessa natureza. Não foram encontradas referências nas literaturas específicas de teletrabalho que relacionassem seus impactos psicológicos. Ademais, os dados aqui presentes podem fornecer embasamento para que gestores de diversas áreas considerem buscar estratégias para implementar ou ampliar o teletrabalho nas instituições, bem como para auxiliar os indivíduos interessados em aderir ao teletrabalho.

Aplicar o DIT aos teletrabalhadores foi um desafio, pois, apesar de conter um quinto do tamanho de seu questionário de origem, o MMPI, as 142 questões do inventário demandam um tempo médio de 25 minutos para que sejam respondidas. Alguns teletrabalhadores manifestaram descontentamento com o tamanho do questionário, e outros sequer chegaram a terminá-lo e tiveram suas participações inviabilizadas. Além disso, a falta de esclarecimento dos prováveis participantes quanto a estarem, ou não, enquadrados na categoria de teletrabalhadores demandou tempo e atenção para a adequação aos critérios, como no caso de um artesão que, até o momento em que foi convidado a participar da pesquisa, não se considerava praticante do teletrabalho. Seu trabalho descreve-se assim: tinha um ateliê em casa, mas expunha e vendia seus produtos em um site de compra e venda na Internet. A partir de acontecimentos como esse, percebeu-se que o termo "teletrabalho" e suas derivações não são largamente reconhecidos, inclusive por muitas das categorias profissionais abordadas. Desta forma, verifica-se a necessidade de maior divulgação do teletrabalho e de suas possibilidades de inserção nos mais diversos segmentos de negócios, bem como de sua correta remuneração e relações justas de trabalho.

A busca por um método não reducionista parte do pressuposto de que o universo de análise é demarcado pela multi, inter e transdisciplinaridade de conhecimentos e, logicamente, não pode ser abordado como um fenômeno isolado e focal (Codo \& Soratto, 1999; Codo, 2002; Codo, Soratto \& Vasques-Menezes, 2004). Para futuras investigações no tema, sugere-se que sejam realizadas as outras etapas do DIT. Além disso, vale considerar a utilização de amostras de categorias mais restritas de teletrabalhadores, uma vez que é ampla a gama de possibilidades em teletrabalho.

\section{Referências}

Alves, D. A. (2008). Gestão, produção e experiência do tempo no teletrabalho. Tese de doutorado, Universidade Federal do Rio Grande do Sul, Porto Alegre.

Barros, A. M. (2007). As implicações do teletrabalho para os indivíduos e para sua forma de atuação na empresa: um estudo de caso dos teletrabalhadores da Shell Brasil. Dissertação de mestrado, Pontifícia Universidade Católica do Rio de Janeiro, Rio de Janeiro.

Boonen, E. M. (2003). As várias faces do teletrabalho. Economia e gestão, 2, 106-127.

Castells, M. (1999). A sociedade em rede (vol. 1). Rio de Janeiro: Paz e Terra.

Castells, M. (2003). A galáxia da Internet: reflexões sobre Internet, negócios e sociedade. Rio de Janeiro: Zahar.

Codo, W. (1988). Saúde mental e trabalho: uma urgência prática. Psicologia, Ciência e Profissão, 8 (2), 20-24.

Codo, W. (1989). Relações de trabalho e transformação social. In S. T. M. Lane \& W. Codo (Orgs.), Psicologia social: o homem em movimento (pp. 136-156). São Paulo: Brasiliense.

Codo, W. (1996). Um diagnóstico do trabalho (em busca do prazer). In A. Tamayo, J. E. Borges-Andrade \& W. Codo (Org.), Trabalho, organizações e cultura (pp. 36-55). São Paulo: ANPEPP.

Codo, W. (2002). Um diagnóstico do trabalho com ênfase em saúde mental. In M. G. Jacques, W. Codo (Orgs.), Saúde mental $\mathcal{E}$ trabalho: leituras (pp. 173-190). Petrópolis: Vozes.

Codo, W. \& Soratto, L. (1999). Saúde mental \& trabalho: uma revisão sobre o método. Psicologia Eु sociedade, 11 (2), 80-96.

Codo, W., Soratto, L. \& Vasques-Menezes, I. (2004). Saúde mental e trabalho. In J. C. Zanelli, J. E. Borges-Andrade \& A. V. B. Bastos (Orgs.), Psicologia, organizações e trabalho no Brasil (pp. 276-299). Porto Alegre: Artmed.

Costa, I. S. A. (2003). Poder/saber e subjetividade na construção do sentido do teletrabalho. Tese de doutorado, Fundação Getulio Vargas, Rio de Janeiro. 
ECaTT. (2000). Electronic commerce and telework trends: benchmarking progress on new ways of working and new forms of business across Europe. Empirica. Bonn, Alemanha. Recuperado em 5 de setembro, 2011, de http://www.ecatt.com/

Estrada, M. M. P. (2010). A realidade do teletrabalho no Brasil e nos tribunais brasileiros. Revista Direito e Liberdade, $12(1), 1-14$.

Ferreira, M. A. (2005). Instituições particulares de ensino superior e docência: uma análise da qualidade da prestação de serviços e sua relação com a subjetividade do docente. Dissertação de mestrado, Universidades Estaduais de Londrina e Maringá, Londrina.

Gambeta, S. S. \& Silva, M. (2007). Tempo, saúde e docência. Dissertação de mestrado, Universidade do Vale do Itajaí, Itajaí.

Goulart, J. O. (2009). Teletrabalho: alternativa de trabalho flexível. Brasília: SENAC.

International Business Machines, IBM. (2010). The globalization of traffic congestion: IBM 2010 commuter pain survey. Armonk. Recuperado em 10 de novembro, 2011, de http://www03.ibm.com/press/us/en/pressrelease/32017.wss.

Jacques, M. G. C. (2007). O nexo causal em saúde/doença mental no trabalho: uma demanda para a psicologia. Psicologia $\mathcal{B}$ Sociedade, 19, Edição Especial, 112-119.

Kitagawa, E. (2005). A subjetividade na administração pública arrecadando o auditor fiscal de tributos. Dissertação de mestrado, Universidades Estaduais de Londrina e Maringá, Londrina.

Lima, M. E. A. (2003). A polêmica em torno do nexo causal em distúrbio mental e trabalho. Psicologia em Revista, 10 (14), 82-91.

Macaciel, W. T. \& Ferraz, F. T. (2004). Teletrabalho na indústria do petróleo: impacto nas condições de trabalho. Encontro Nacional de Engenharia de Produção, 24 (pp. 1075-1082). Florianópolis.

Malvezzi, S. (2004). Prefácio. In J. C. Zanelli, J. E. Borges-Andrade \& A. V. B. Bastos (Orgs.), Psicologia, organizações e trabalho no Brasil (pp. 13-17). Porto Alegre: Artmed.

Marx, K. (1996). O capital (livro 1, tomos 1 e 2). São Paulo: Abril Cultural.

Mello, A. (2011). O uso do teletrabalho nas empresas de call center e contact center multiclientes atuantes no Brasil: estudo para identificar as forças propulsoras, restritivas e contribuições reconhecidas. Tese de doutorado, Universidade de São Paulo, São Paulo.

Mill, D. (2006). Educação à distância e trabalho docente virtual: sobre a tecnologia, espaços, tempos, coletividade e relações sociais de sexo na Idade Mídia. Tese de doutorado, Universidade Federal de Minas Gerais, Belo Horizonte.

Miranda, B. S. (2002). Diagnóstico integrado do trabalho: um estudo de validação. Dissertação de mestrado, Universidade de Brasília, Brasília.

Nasio, J. D. (1991). A histeria: teoria clínica e psicanalítica. Rio de Janeiro: Jorge Zahar.

Nohara, J. J., Acevedo, C. R., Ribeiro, A. F. \& Silva, M. M. (2010). O teletrabalho na percepção dos teletrabalhadores. Revista de Administração e Inovação, 7 (2), 150-170.

Oliveira, S. F. L. (2009). Conflito trabalho-família e o uso de práticas de suporte instrumental em empresas fabricantes de eletroeletrônicos de Caxias do Sul. Dissertação de mestrado, Universidade de Caxias do Sul, Caxias do Sul.

Pereira Jr., E. \& Caetano, M. E. S. (2009). Implicações do teletrabalho: um estudo sobre a percepção dos teletrabalhadores de uma região metropolitana. Revista Psicologia: Organização e Trabalho, 9 (2), 22-31.

Pinto, J. O. (2003). Avaliação da viabilidade de implantação do teletrabalho no domicílio: um estudo de caso no SERPRO. Dissertação de mestrado, Universidade Federal de Santa Catarina, Florianópolis.

Rosenfield, C. L. (2005). Autonomia e trabalho informacional: o teletrabalho. Encontro Anual da Associação Nacional de Pós-graduação e Pesquisa em Ciências Sociais, 29 (pp. 1-19). Caxambu.

Silva, R. R. (2009). Home-officer: um surgimento bem-sucedido da profissão pós-fordista, uma alternativa positiva para os centros urbanos. Revista Brasileira de Gestão Urbana, 1 (1), 85-94.

Smaha, H. C. (2009). Trabalho e família no contexto do teletrabalho: o olhar de teletrabalhadores e seus co-residentes. Dissertação de mestrado, Fundação Getulio Vargas, Rio de Janeiro.

\section{Endereço para correspondência}

r.almeidafonseca@gmail.com,pereznebra@gmail.com 